Industrial Pulmonary Disease has studied the problem of silicosis in South Wales miners and also the environment of these workers. Dr. D'Arcy Hart summarizes the resultant additions to our knowledge of this problem and the Committee's recommendations. Readers interested in other work being done to increase the safety of the mines will find useful the Ministry of Fuel and Power's annual report for 1942 of the Safety in Mines Research Board (London : H.M. Stationery Oifice, 1943. 1s. net), which deals with work on coal-dust and fire-damp explosions, mining explosives, falls of ground, electrical researches and kindred problems.

In the same issue of the British Medical Bulletin Mr. R. C. Brock writes a valuable article on the present position of thoracic surgery. The advances in this field in recent years have been remarkable, and the surgical treatment of tuberculosis has an important place among them. Mr. Brock names $\mathrm{X}$-rays and anæsthesia as the twin pillars of thoracic surgery, which requires of the surgeon such a wide knowledge of the anatomy and physiology of the chest as well as his essential pathological and medical experience. The anæsthetist has the especially difficult job of maintaining respiration and the circulation of the blood during operations on the very organs which maintain these essential functions. Mr. Brock thinks that, during the next ten years, we shall see advances in the surgery of the heart and cosophagus as great as those which have occurred in thoracic surgery during the past ten years. A good idea of the quality of the anatomical research on which thoracic medicine and surgery are based is given by the succeeding illustrated article on the anatomy of the bronchi by Dr. A. F. Foster-Carter. Excellent bibliographies add to the value of all these articles. They are supplemented by reviews of selected articles on pulmonary anatomy, surgery and disease, and on further papers on tuberculosis in children and on the statistical and social aspects of this outstanding scourge of our civilization.

The results of further important work on various aspects of tuberculosis have been published in The Lancet and the British Medical Journal during recent months and we know, from reports on the health of the occupied countries, how important a factor tuberculosis will be in the immense task of reconstruction after the War. A correspondent of The Lancet (Fob. 12, 1944, p. 225), taking his information from French underground medical papers, states that tuberculosis has increased in that country by at least 20-30 per cent. French medical men, moved to horror by the ever-increasing number of French workers deported to Germany who return with tuberculosis, are unable to save their lives because the necessary diets and drugs are not available. They are trying to sabotage the deportations by ordering long rest-cures, laboratory investigations, consultations with absent specialists and similar means. The discussion on nutrition in enemy-occupied Europe at the meeting of the Royal Society of Medicine on November 23, 1943 (The Lancet, Dec. 4, 1943, p. 703, and Proc. Roy. Soc. Med., 5, 37, Jan. 1944, p. 113) reveals a similar grave situation in Greece, JugoSlavia and Belgium. In the U.S.S.R. the problem is being tackled partly by village settlements similar to the English settlements at Papworth and Preston Hall, but the Russians appear to be concentrating on large-scale rehabilitation in and around the normal sites of industry (Brit. Med. J., Nov. 20, 1943, p. 652).

G. LAPAGE.

\section{SCIENCE CLASS LECTURE CINE-FILMS}

A PARAGRAPH in the News and Views column $A$ of Nature of November 27, 1943, p. 623 , referred to a ciné-film showing the Brownian movement Dr. Quintin Moore, Mr. Thos. Smith Wylie; and Mr. Frank G. Conway, of the Royal Technical College, Glasgow, have given the following particulars regarding the method and apparatus.

Microscopical Unit. Through the courtesy of the Royal Technical College, Glasgow, we had the use of a 'Siedentopf' Cardioid Ultra-microscope (manufactured by Carl Zeiss) together with associated apparatus.

The source of light was a 15-amp. carbon are with a horizontally positioned positive carbon. A converging lens projected the light as a parallel beam. The light passed through a cooling chamber containing slightly acidulated 20 per cent ferrous ammonium sulphate solution, then directly to the 'Cardioid Condenser', which was fitted into the sleeve of the Abbe illuminator of the microscope. The top of the condenser was connected to the object slide by a layer of distilled water.

A $1 \mathrm{~mm}$. thick quartz slide and quartz cover formed a chamber which was mounted in a metal holder and held firmly against the stage of the microscope. This quartz chamber resembles that of a hæmocytometer slide without engraved ruling; but the depth is considerably less, only $2-4 \mu$ deep. A colloidal solution of Carey Lea's silver, suitably diluted, was placed on the centre of the object slide and excess solution overflowed into the surrounding channel. The dimensions of the colloidal silver particles were of the order of $50 \mathrm{~m} \mu$.

By careful adjustment and focusing, the oblique light from the condenser was made to illuminate completely the thin stratum of colloidal solution in the chamber. None of this oblique light can enter the microscope directly, due to the high numerical aperture of the objective. The light which does enter is scattered from the surfaces of the colloidal particles and it passes into the following microscopical combination: an apochromatic glycerine immersion objective adapted for use with the thick quartz cover and of magnification 58, focal length $3 \mathrm{~mm}$., and numerical aperture $0 \cdot 85$. The objective, carried by a centring nosepiece, was used in conjunction with a compensated focusing eyepiece, and the combination gave a magnification of 1,160 diameters.

Photographic Unit. This consisted of a Bell-Howell $16 \mathrm{~mm}$. camera fitted with a $f 1.5$ lens of 1 inch focal length.

The camera was mounted on a heavy base and carefully set up so that the lens combinations of the microscope and camera were in accurate co-axial alignment. The camera lens set to infinity and at full aperture was placed in a ground glass focusing mount, which in turn was clamped to the eyepiece of the microscope. Through this combination the microscope was focused. The lens was then replaced in the camera, maintaining the same relative positions of lens and eyepiece.

Kodak Super XX reversal panchromatic film was used with a camera frame speed of 4 per sec., giving an exposure of approximately $\frac{1}{8}$ sec. per frame. No filters were used.

Excellent darkground effects were obtained with the above equipment provided the requisite care was 
taken in the alignment of the microscope and the cleaning of the quartz chamber.

Copies of this instructional film (screening time about $4 \mathrm{~min}$.) can now be hired from the Scottish Central Film Library, 2 Newton Place, Glasgow, C.2.

\section{CONTROL OF ST. JOHN'S WORT IN AUSTRALIA*}

By DR. A. D. IMMS, F.R.S.

$\mathrm{F}^{1}$ IVE species of St. John's wort (Hypericum) occur in Australia - mainly in Victoria and New South Wales. These species are $H$. perforatum L., $H$. androscmum L., $H$. calycium L., $H$. gramineum Forst. and $H$. japonicum Thunb. The first-named is by far the most widespread and the chief pest. Between 250,000 and 400,000 acres of land in Victoria and very large areas in New South Wales are in. fested with $H$, perforatum, and it also occurs in South Australia, Tasmania and Western Australia. The species was introduced in 1870 in Victoria, and since it occurs chiefly in hill and plateau country it is one of the most injurious of Australian weeds. Growing thickly, it eliminates all low-growing vegetation including pasture grasses, and some of the areas covered by the weed have had to be abandoned. It is, furthermore, poisonous to stock.

Several methods of controlling $H$. perforatum have been adopted in Australia and some success has been achieved by the application of common salt at the rate of ten, or more, tons to the acre. This treatment, however, is too expensive for general use although it is employed in Victoria to keep the roadsides free from the weed. The possibility of its repression by insects was first taken into account in 1917, and certain species of Hypericum-feeding insects were introduced in succeeding years from England. These were certain beetles of the family Chrysomelidæ- the species Chrysolina varians Schell., $C$. brunsvicensis Grow. and $C$. hyperici Forst., all of which are leaffeeders. The Geometrid moths Anaitis efformata Guen. and $A$. plagiata L., the larvæ of which feed on the foliage of Hypericum, were also introduced from England. None of these appeared to become established and the primary cause of the failure of most of them appeared to be climatic.

Attention was then directed to Hypericum insects in southern France, where field observations showed that a high degree of control is achieved in particular places by the Buprestid beetle Agrilus hyperici Creutz. and the Chrysomelid beetle Chrysolina gemellata Rossi. Supplies of both these species were shipped to Australia in 1939 and 1940. The species Chrysolina hyperici disappeared for some years after its libera. tion, but has since been found in large numbers and is now firmly established in many areas.

None of the other species of insects introduced from England has apparently become established. While $C$. hyperici now occurs in many localities, as yet it only occupies a mere fraction of the total Hypericum area of Australia. C. gemellata became very readily established and spread and the Agrilus hyperici gives great promise and is increasing rapidly in several of the areas where its original liberation took place in 1939 and 1940. At present, however, the area actually covered by these last two species * The Entomological Control of St. John's Wort (Hypericum per-
foratum L.) by Frank Wilson. Bull. No. I69 Council for Scientiflc and Industrial Research (Melbourne, 1943). is even smaller than that covered by $C$. hyperici. There is every prospect that the three species named will eventually occur in all the St. John's wort areas. Their present limited distribution is naturally to be expected because they have only been introduced during a brief period. The retrogression of the weed where $C$. hyperici is numerous and the continuous increase in the numbers of this insect, together with the ease with which the other species $(C$. gemellata and $A$. hyperici) have become established, give ground for confidence that a useful degree of control of the weed will, in time, be achieved.

\section{STRUCTURE, FUNCTION AND SYNTHESIS OF POLYSACCHARIDES*}

$\triangle$ NEW chemical synthesis of cellobiose by a A simple and direct method has been accomplished by Stacey and Gilbert. The structure of the repeating unit in cellulose is therefore well established, and the microbiological synthesis of the polysaccharide was achieved by Hibbert. Starch, another functional material of the plant, is recognizable as two structural types of polysaccharide: amylose giving the deep blue coloration with iodine and representing about 25 per cent of natural starch, and amylopectin, the remaining 75 per cent, giving a reddish-blue colour. Amylose, synthesized both by plant and muscle phosphorylase, is represented as a continurous chain of maltose units and this is completely hydrolysed to maltose by $\beta$-amylase. Amylopectin is also composed of maltose units in shorter chains which are united as a laminated or branched-chain structure, and this is hydrolysed in stages to maltose and various dextrins. The factor responsible for the synthesis of amylopectin has not yet been isolated, but attempts have been made in this direction. Products related to amylopectin have been obtained by Dr. Peat, but their identity is not yet established.

Many of the specific and somatic bacterial polysaccharides contain amino-glucose and uronic acids as constituent units. The constitutional relationship of these polysaccharides is only partly revealed, although some synthetic analogues which are bioses are seen also to have antigenic properties. Structurally related to these are the polysaccharides produced by non-pathogenic organisms such as Rhizobia; and the plant gums which also contain uronic acid groups.

Heparin, the blood anti-coagulant factor of liver, contains glucosamine and glucuronic acid units together with acetyl and sulphate residues. The chondroitin of cartilege is similar in the composition of its individual units except that galactosamine (or talosamine) replaces glucosamine.

The synthesis of the levans by enzymes has been frequently reported; their constitution is now established, as is also that of the dextrans from Penicillium luteum and Leuconostoc dextranicum. These are $1: 6$-glucopyranose polymers.

$B$. welchii, the gas gangrene organism, is convertible into a Gram-negative form by sodium cholate ex. traction. The Gram-positive character can be restored by combination with the magnesium salt of ribonucleic acid. The constitution of both this acid and desoxy-ribonucleic acid is partly revealed by the recognition of ribo- and desoxyribofuranose units, the mode of combination of which, whether single or linked units, is not yet known.

* Substance of the Bakerian Lecture delivered before the Royal Society by Prof. W. N. Haworth, F.R.S., on June 15. 